\title{
DEVELOPMENT AND IMPLEMENTATION OF INNOVATIVE EDUCATIONAL MODULES ON ARCHITECTURAL PHOTOGRAMMETRY FOR BACHELOR'S DEGREE CURRICULA IN ARCHITECTURE
}

\author{
R. Shults
}

Kyiv National University of Construction and Architecture, Faculty of GIS and Land Management, Povitroflotskyi Avenue, 31 Kyiv, 03037, Ukraine-shultsrv@gmail.com

\section{Commission V, WG V/7 \& Commission IV, WG IV/6}

KEY WORDS: Architecture, 3D modeling, Architectural Photogrammetry, Curriculum

\begin{abstract}
:
Modern specialists in the field of architecture work exclusively in three-dimensional space. At the same time, their training completely ignores the state-of-the-art technologies associated with obtaining three-dimensional models of engineering structures. In such circumstances, the connections between the three key participants in the design and construction of engineering structures, namely architects, builders, and surveyors are broken. The main technology that allows obtaining three-dimensional models is photogrammetry. The purpose of the presented article is to determine the subject matter of close-range photogrammetry in solving architectural design problems. Based on certain architectural tasks, educational modules for the discipline of architectural photogrammetry of the bachelor educational level were developed. The peculiarity of the proposed program is that it is designed in such a way that it allows using the whole complex of the modern achievements in the field of automated image processing and the specifics of setting and solving architectural problems. At the same time, this program covers such modern technologies and concepts as UAV photogrammetry, digital photogrammetry, photogrammetric scanning, BIM, GIS, etc. Such an approach allows students without problems to learn several special knowledge, which is owned by surveyors and photogrammetrists. The approximate content of the course of architectural photogrammetry for bachelor students is presented.
\end{abstract}

\section{INTRODUCTION}

One of the topics of modern architects and civil engineers is the necessity to have a complex knowledge in the field of photogrammetric technologies. It was long years ago when both architects and surveyors used to use only "paper" technologies. They both used to work with paper drawings, create projects, and setting-out them on site. Since that time, a significant breakthrough in technologies has happened. Surveyors and photogrametrists, particularly, have moved to digital technologies and using them for data gathering and output. The same things have been going with architects for the last twenty years. However, if, in the case of "paper" technologies, they were a common base for surveyors and architects, in a digital era, there is an issue in the understanding and treating of different data that provide architects and surveyors each other. Probably, the most famous example of such a dispute is a discussion about building information modeling (BIM) (Logothetis et al. 2015, Banfi et al., 2017, Han et al. 2017). For architects, BIM is, first of all, a detailed 3D model; on the other hand, for civil engineers, BIM is more than just a model. It is a passport of the structure with facilities, communications, loads, and even deviations from the project. At the same time, for civil engineers, the level of detail does not play such an important role for architects. The main demand is an accurate position of the structural elements and facilities, both absolute and relative. Somewhere in between is a place of surveyors. To be on the same page, surveyors have to understand the architects and civil engineers' tasks and requirements. But, it does not mean that this is a peculiar problem of surveyors. Quite the contrary, to set up the tasks correctly, the architects must realize the surveyors' opportunities and constraints. That is why it is badly needed for modern architects to be acquainted with state-of-the-art surveying and photogrammetric technologies. One of the ways to reach out to this purpose is to establish a special course for young students of architectural majors that will allow understanding the surveyors' capabilities. From our experience, such a course that bears all the necessary components could be called architectural photogrammetry. The presented paper is a part of WGV/7 research. Last years the works dedicated to the problem of the development and implementation of innovative educational modules on architectural photogrammetry for bachelor's degree curricula in architecture had been published (Shults 2017, Shults et al., 2017, Levin et al., 2016, Kravchenko et al., 2016 ). But of course, theses educational modules are based on some fundamental works such as (Luhmann et al. 2014). It is obvious that not the last role for this course plays ubiquitous low-cost technologies namely low-cost photogrammetry (Alessandri et al., 2019, Gaiani et al., 2019, Zacharek et al., 2017, Santise et al., 2017, Ancona et al. 2015, Kersten et al. 2015, Hassani and Rafiee 2013) and UAV technologies (Azzola et al., 2019, Murtiyoso et al., 2017). So, the primary goal of the paper is curriculum development for the architectural photogrammetry course. This course will include the last achievements in photogrammetric science in conscience form. To start the curriculum development, it is necessary to identify common photogrammetric tasks.

\section{ARCHITECTURAL PHOTOGRAMMETRY TASKS CLASSIFICATION}

Any new course commences from concept development that we have done in the introduction. Then it follows learning objectives and ends up with a curriculum. To set the learning objectives, one has to understand general applications of architectural photogrammetry and common problems (Patias et al., 2013, Hassani 2015).

\begin{tabular}{|l|}
\hline \multicolumn{2}{|c|}{ Architectural photogrammetry } \\
\hline Landscape design \\
\hline Architectural measurements \\
\hline Restoring objects (including archive imageries) \\
\hline $\begin{array}{l}\text { Documentation of architectural monuments and } \\
\text { archeological sites }\end{array}$ \\
\hline Figure 1. Common applications of architectural photogrammetry \\
\hline
\end{tabular}


According to Figure 1, let us see more deeply to each of these applications and name a few of them.

Landscape design may be the first or the last step of architectural design, depending on a project stage. Common tasks during landscape design are:

1. Drawing up plans for town planning documentation.

2. Creation of $3 \mathrm{D}$ models for a vertical design.

3. Creation of 3D models for projects of geoplastics.

Architectural measurements are the most widespread application of architectural photogrammetry (Azzola et al., 2019, Kersten et al., 2015). Common tasks during architectural measurements are:

1. Architectural measurements of the facade. Vertical drawings.

2. Architectural measurements of the facade. Horizontal drawings.

3. Architectural measurements of the interior.

4. Architectural measurements of sculptures.

5. Representation of the architectural objects in the form of contours.

6. Drawing up orthophotomaps of architectural structures.

7. Architectural structures 3D modeling.

Restoring objects by archive imageries is a particular application that needs a strong liaison of architects with surveyors and civil engineers (Genin 2019, Fiorillo et al., 2013).

Common tasks during the restoration of the objects by archive imageries are:

1. Restoration. Restoring the form of lost elements.

2. Creation of a database for models of architectural structures. Certification of architectural objects.

3. Security measures for historical, architectural, and cultural objects.

4. Archiving of museum exhibits.

5. Research of structures by models.

The last but not least application is documentation of architectural monuments and archaeological objects (Alby et al. 2013, Gonizzi Barsanti et al., 2013). Common tasks during the documentation are:

1. Drawing up a plan for archaeological excavations.

2. Non-contact measurements of archaeological findings.

3. Restoration of the primary form of archaeological findings.

4. Drawing up archives of models of archaeological objects.

5 . Research of natural monuments and cultural objects.

6. Determination of the shape and size of natural monuments.

7. Definition of the connection of natural monuments with the environment.

8. Determination of the qualitative and quantitative characteristics of natural monuments.

9. Creation of archive of models of natural monuments.

10. Revealing hidden structures.

This list is no means exhaustive. However, it gives a general view of a problem and opens the ways how to organize the course content and its structure.

\section{NEW EDUCATIONAL PROGRAM}

According to the tasks mentioned earlier, the learning objectives, course items, and lab works content have been developed. The primary intention of the course the Architectural photogrammetry is to build up modern architects and scientists and to get them acquainted with a powerful tool for the solution of miscellaneous applied architectural and engineering tasks employing state-of-the-art photogrammetry. The course consists of five parts; it starts with a brief introduction about photogrammetry. Then follow basic concepts and math background. Keeping in mind that this course is intended for newcomers (first tear students), we have tried to put across the sophisticated math and used a basically geometric approach to present math background. The third part comprises the equipment review, including UAV and terrestrial laser scanning. The photogrammetric fieldwork preparation being considered in the fourth part. The fifth part includes data capturing, organization, importing, exporting, and integration. It is paid much attention to drawings and 3D modeling. Each piece of the course accompanies with examples of real data processing.

The educational program has the following items:

1. The basic concepts of GIS and BIM.

2. Introduction to architectural photogrammetry. Tasks classification. A brief history of the photogrammetry.

3 . The basic math of architectural photogrammetry.

4. State-off-the-art digital cameras and software for data processing and modeling.

5. The main characteristics of digital cameras and calibration procedure.

6. A brief review of UAV technologies.

7. A brief review of terrestrial laser scanning.

8. Calculation of the field surveying parameters and the anticipated accuracy.

9. Data capturing.

10. Data processing.

11. Data integration.

Except for the theory, the major part of the program consists of lab works. These lab works in a complex look as a course project. The offered content of the lab works are:

Lab \#1 Object description, conditions, and specific architectural requirements, preliminary accuracy calculation.

Lab \#2 Fieldworks planning and deploy. For the real object of surveying, students calculate surveying parameters for different surveying methods (close-range photogrammetry, terrestrial laser scanning, UAV, etc.), study the technology of data capturing, plan and perform its measurements.

Lab \#3 Non-metric camera calibration. The calibration carries out by software using plane test objects.

Lab \#4 Fieldworks. For the chosen object (building, monument, sculpture, etc.)

Lab \#5 Data processing and 3D modeling.

Lab \#6 Terrestrial laser scanning of historical monuments. This lab includes just fieldwork that is based on preliminary information from lab 2.

Lab \#7 UAV surveying of historical monuments. This lab includes just fieldwork that is based on preliminary information from lab 2.

Lab \#8 Data processing and integration. The aim of this work is data processing from labs 6 and 7, and its integration for complex 3D modeling.

Such a structure allows us to reach out to the course learning objectives. It means that upon successful completion of this course, students will be able to:

- $\quad$ analyze the results of photogrammetric measurements and assess data quality by standard statistical models;

- build charts, drawings, maps, 3D models by the results of photogrammetric measurements;

- $\quad$ apply the state-of-the-art photogrammetric equipment and software

- $\quad$ set up and solve conventional architectural tasks;

- describe the architectural photogrammetry methods and opportunities.

Using this course structure, under supervising of ISPRS WGV/7 in Kyiv National University of Construction and Architecture, 
has been carried out a couple of projects. All of them were realized by university students. Let us have a look at some of them.

\section{SAMPLE PROJECTS OF THE NEW EDUCATIONAL PROGRAM}

The first project was done for a historical object in the center of Kyiv. The object was a building of Mariinskiy Palace that was built in the XVIII century. The main goal of this project was a creation of the facade horizontal drawings. To achieve this goal, photogrammetric surveying of the facade of the Mariinskiy Palace had been done (Figure 2).

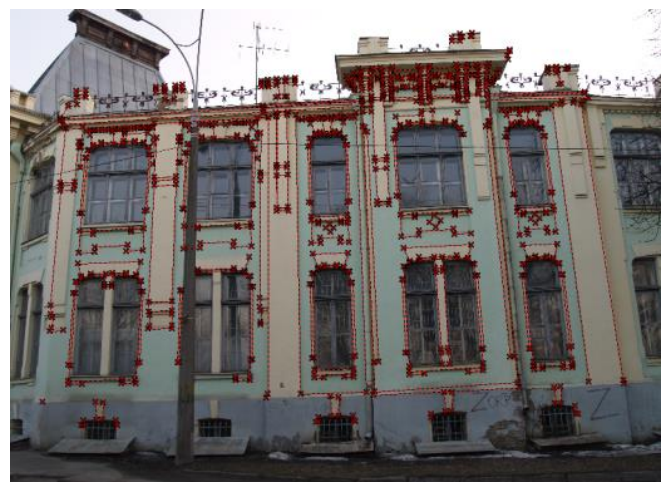

Figure 2. Architectural measurements overlaid on the real structure

For surveying, a non-metric digital camera was used. On the facade, more than 100 reference points were measured by the total station. So that each imagery had 6-8 reference points at least. Photogrammetric modeling has been done by the educational version of PhotoModeler software. Camera calibration was done by PhotoModeler calibration tool and plane test object. The drawings were exported to AutoCAD for the final refinement (Fig. 3).

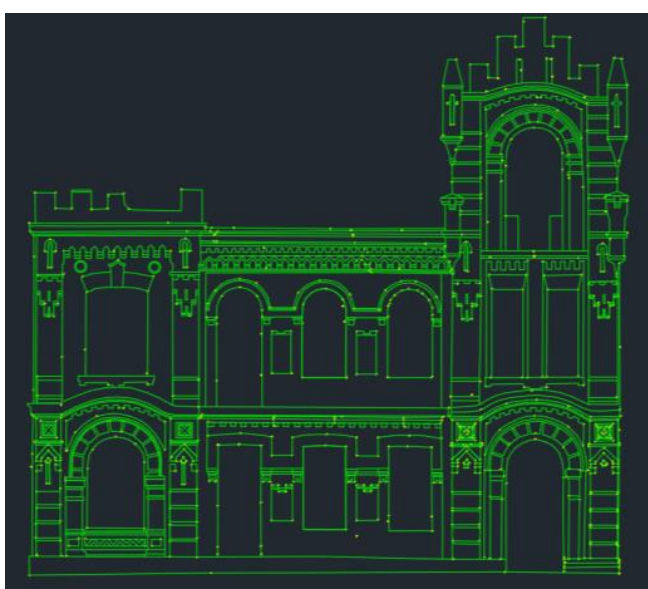

Figure 3. Architectural measurements of the façade

A similar project was accomplished for the main governmental building in Ukraine. It is a 10-story building of the Cabinet of Minister of Ukraine. This building was built before the Second World War. The same set of equipment and software was used. Again over 50 reference points were measured by total station. As a result, not only horizontal drawings were constructed, but also the 3D model was built (Figure 4) using PhotoModeler modeling tools. The final accuracy for both of these projects depends on the accuracy of geodetic measurements, surveying distances, quality of the calibration, and camera parameters. For the first object the final accuracy after adjustment was equal to $14 \mathrm{~mm}$ and for the second one $34 \mathrm{~mm}$. Students have learned how to plan measurements, gathering data, processing and modeling data, and create the final product (drawings, 3D models, etc.).

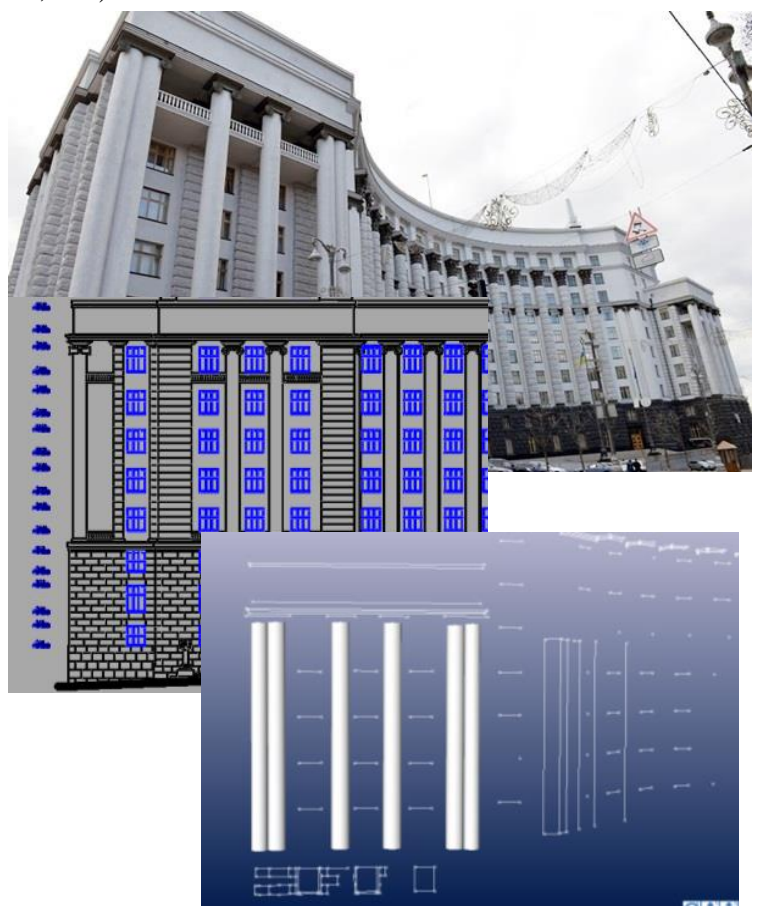

Figure 4. Architectural measurements of the façade. Vertical drawing vs. 3D model

According to the list of the architectural photogrammetry tasks, were performed surveying and data processing of typical private houses with the aim of reconstruction and architectural design (Figure 5 and Figure 6).

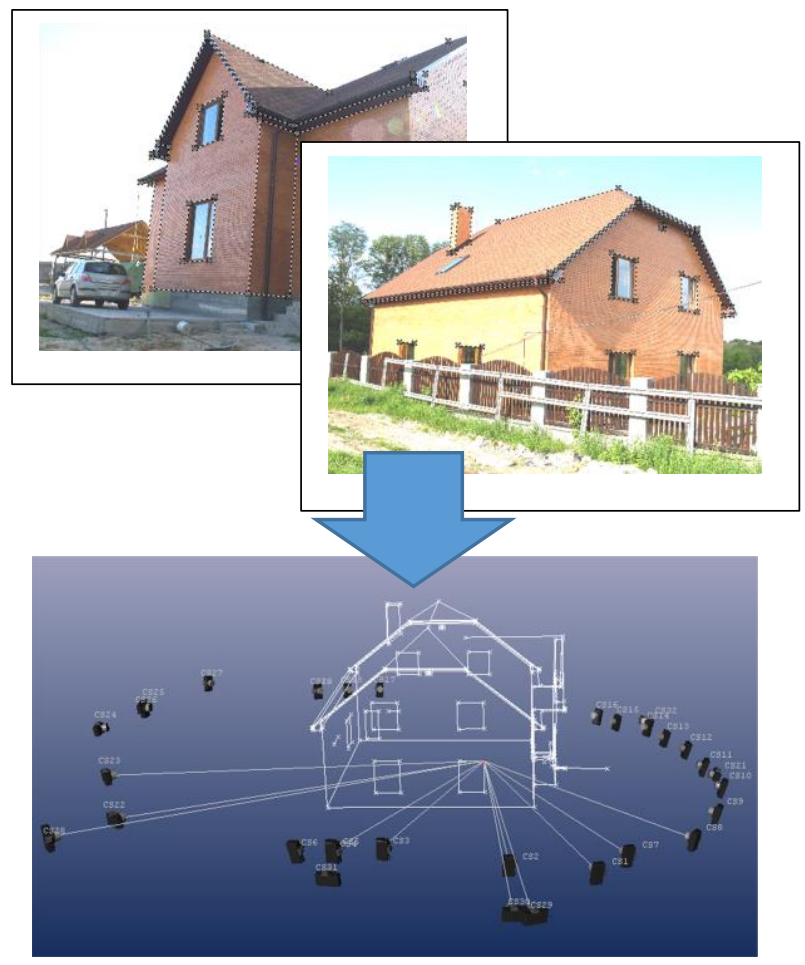

Figure. 5. Data gathering for a reconstruction project 

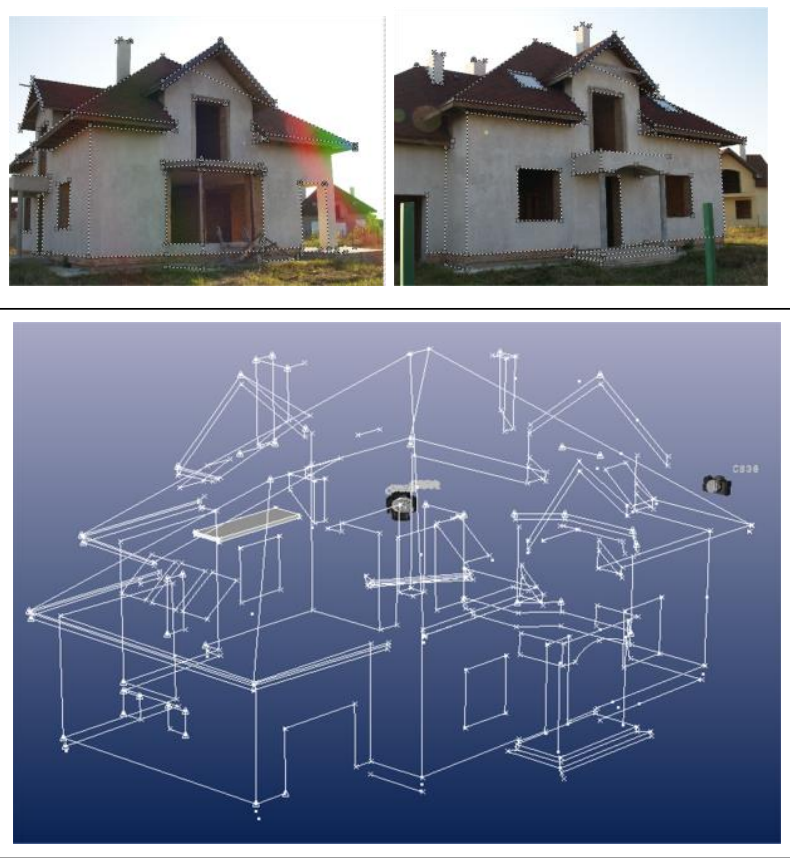

Figure 6. Data gathering for architectural design project

For this project, students have used a non-metric digital camera, done its calibration, and processed data in PhotoModeler software. For the 3D model scaling, the Leica EDM was used. The necessary accuracy at the level of 5-10 $\mathrm{mm}$ was reached out. One of the things that students learned was the effect of bad camera geometry on the final results.

The more complicated and interesting project was accomplished last year. It is an architectural measurement of sculptures using different data sources and their integration. The sculpture (Figure 7, a) was surveyed by three different devices. The first data set had been got by terrestrial laser scanning using Leica

C10 (Figure 7, b), the second one using scanner BLK 360 (Figure $8, a$ ), and the third one using surveying from UAV DJI Phantom 4 (Figure 8, b).
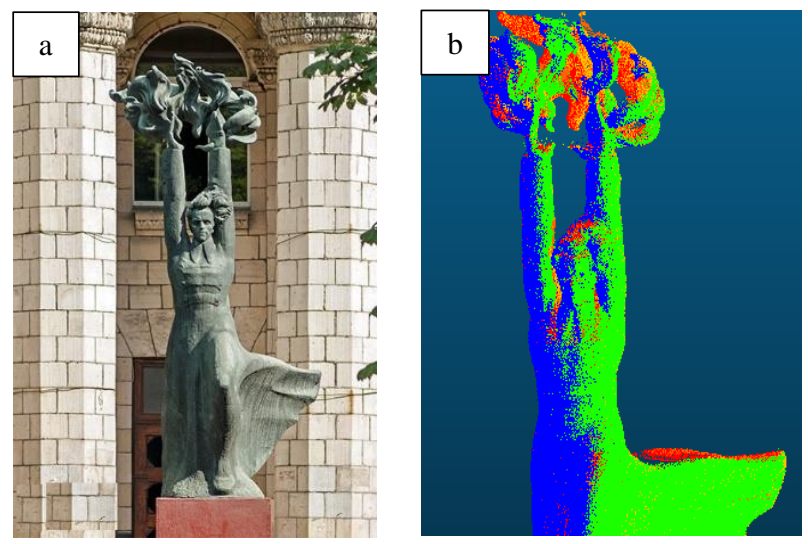

Figure 7. Architectural measurements of sculptures: (a) historical monument; (b) point cloud from Leica C10.

For both sets of scanning data, the processing was carried out in the open-source software CloudCompare. The UAV's data were processed in the educational version of AgiSoft Photscan software. To scaling the photogrammetric model, two different strategies were realized. For the first case, five vertical distances were measured by EDM. For the second case, the photogrammetric point cloud was exported to Cloud Compare and overlayed by point cloud from terrestrial laser scanning by Leica C10.
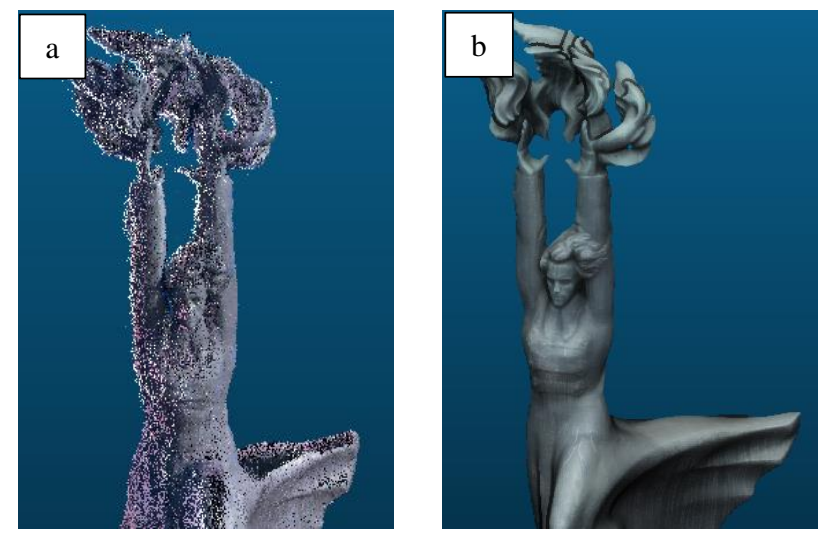

Figure 8. Architectural measurements of sculptures: (a) point cloud from BLK 360; (b) point cloud from DJI Phantom 4.

With the aim of comparison, all data sets were compared using the cloud to cloud algorithm. As a reference point cloud, the cloud created by Leica C10 was accepted. The results of this comparison are presented in Figure 9.

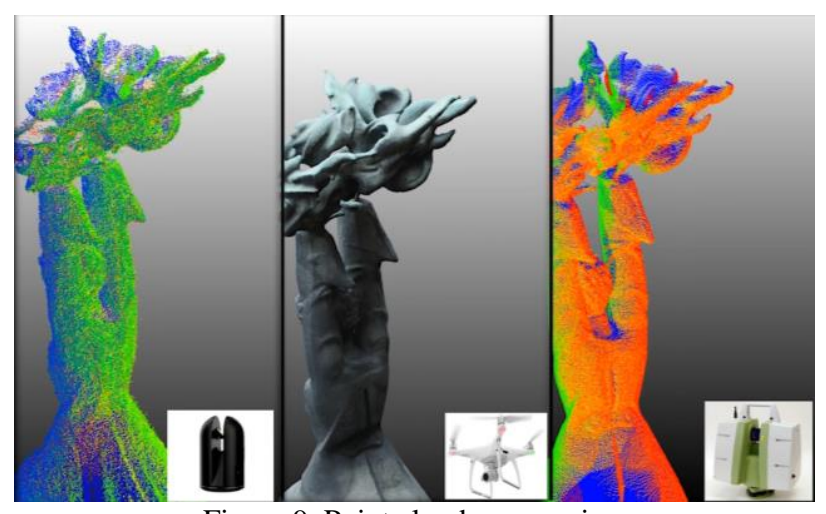

Figure 9. Point clouds comparison

The root mean square error relative to the reference point cloud was equal to $11 \mathrm{~mm}$ for DJI Phantom 4 data and $21 \mathrm{~mm}$ for DLK 360 data. The key learning objectives for the students were gathering and processing UAV data, and integration of terrestrial laser scanning and UAV data.

The final project that it is worth to mention is drawing up plans for archaeological excavations and findings. The project was accomplished for the complex of fortified structures of the Second World War near Kyiv (Figure 10).

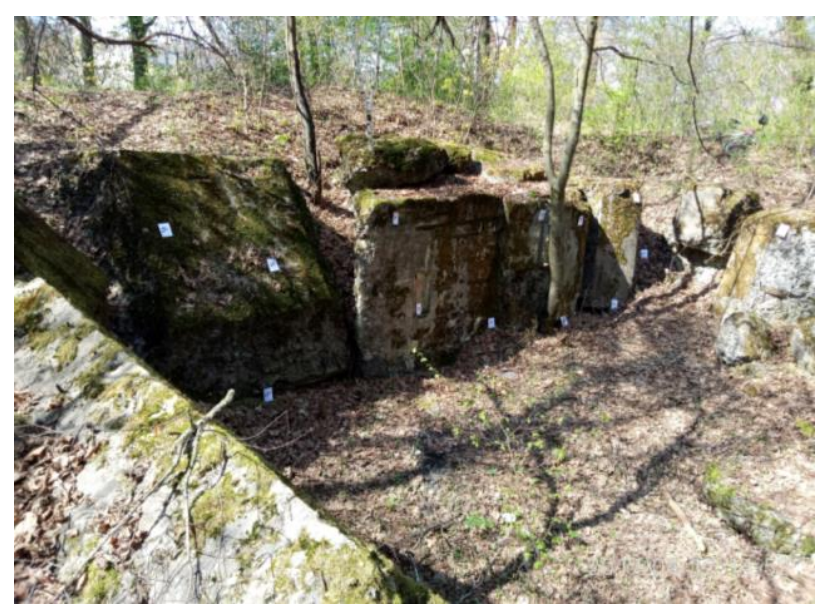

Figure 10. The image of historical fortified structure 
For the students, the key feature of the project was using coded targets for automatic imageries orientation. To scaling the photogrammetric model, ten vertical and horizontal distances were measured by EDM. Finally, the 3D point cloud (Figure 11) was generated by AgiSoft Photoscan.

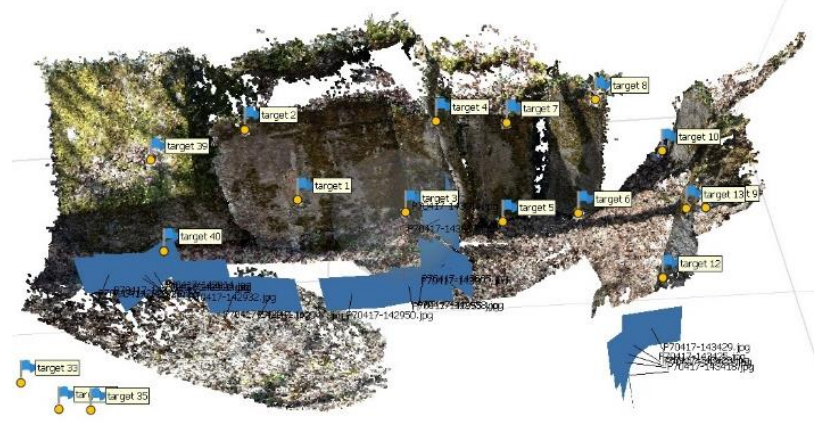

Figure 11. Point cloud of historical fortified structure

Summing up, it is necessary to point out a high quality of performed works and its high applicability to real architectural tasks.

\section{CONCLUSIONS}

First of all, it is necessary to point out that the effectiveness of the developed course of architectural photogrammetry was assessed very positively by employees of different architectural companies who were engaging our students for summer practice and part-time works. They proved students' high skills in the field of architectural measurements and offered some useful suggestions that were accounted for in the course structure.

After the implementation of this educational course, the next step has to be the development of the course resources. Among such resources could be e-textbook, sample test data sets, and an online learning platform. To support this course, it is badly needed to organize seminars and workshops that would help to reach one of the primary aims of our work, namely the creation of liaison between architects and surveyors.

The results and experience that have presented above will be useful to students and teachers of other universities. The given concept and structure may help in the organization of new courses for other non-geospatial majors, e.g., civil engineering or the upgrading of current courses.

\section{REFERENCES}

Alby E., Elter R., Ripoche C., Quere N. Close range photogrammetry applied to the documentation of an archaeological site in Gaza Strip, Palestine. Int. Arch. Photogramm. Remote Sens. Spatial Inf. Sci. 2013. Vol. XL5/W1. P. 19-24. https://doi.org/10.5194/isprsarchives-XL-5W2-19-2013

Alessandri L., Baiocchi V., Del Pizzo S., Di Ciaccio F., Onori M., Rolfo M.F., Troisi S. Three-dimensional survey of Guattari cave with traditional and mobile phone cameras. Int. Arch. Photogramm. Remote Sens. Spatial Inf. Sci. 2019. Vol. XLII2/W11. P. 37-41. https://doi.org/10.5194/isprs-archives-XLII-2W11-37-2019

Ancona M., Clini P., Dellacasa A., Falzone P., La Camera A., Quattrini R., Sommariva E., Stephens J. Extending a mobile device with low-cost 3D modeling and building-scale mapping capabilities, for application in architecture and archaeology. Int. Arch. Photogramm. Remote Sens. Spatial Inf. Sci. 2015. Vol. XL-5/W4. P. 453-459. https://doi.org/10.5194/isprsarchivesXL-5-W4-453-2015
Azzola P., Cardaci A., Mirabella Roberti G., Nannei V.M. UAV photogrammetry for cultural heritage preservation modeling and mapping Venetian Walls of Bergamo. Int. Arch. Photogramm. Remote Sens. Spatial Inf. Sci. 2019. Vol. XLII-2/W11. P. 45-50. https://doi.org/10.5194/isprs-archives-XLII-2-W9-45-2019

Banfi F., Fai S., Brumana, R. BIM automation: advanced modeling generative process for complex structures. ISPRS Ann. Photogramm. Remote Sens. Spatial Inf. Sci. 2017. Vol. IV2/W2. P. 9-16. https://doi.org/10.5194/isprs-annals-IV-2-W2-92017

Fiorillo F., Remondino F., Barba S., Santoriello A., De Vita C.B., Casellato A. 3D digitization and mapping of heritage monuments and comparison with historical drawings. Int. Arch. Photogramm. Remote Sens. Spatial Inf. Sci. 2013. Vol. II-5/W1. P. 133-138. https://doi.org/10.5194/isprsannals-II-5-W1-1332013

Gaiani M., Apollonio F.I., Fantini F. Evaluating smartphones color fidelity and metric accuracy for the 3D documentation of small artifacts. Int. Arch. Photogramm. Remote Sens. Spatial Inf. Sci. 2019. Vol. XLII-2/W11. P. 539-547. https://doi.org/10.5194/isprs-archives-XLII-2-W11-539-2019

Genin S.M. Photogrammetry: methods of survey and applications on restoration works. Int. Arch. Photogramm. Remote Sens. Spatial Inf. Sci. 2019. XLII-2/W11. P. 557-564. https://doi.org/10.5194/isprs-archives-XLII-2-W11-557-2019

Gonizzi Barsanti S., Remondino F., Visintini D. 3D surveying and modeling of archaeological sites - some critical issues. Int. Arch. Photogramm. Remote Sens. Spatial Inf. Sci. 2013. Vol. II5/W1. P. 145-150. https://doi.org/10.5194/isprsannals-II-5-W1$145-2013$

Han S., Wu C., Li D., Li J., Liu Y., Feng K., Di Y. Workflows for condition inspection documentation of architectural heritage based on HBIM: taking three duty rooms in Forbidden City of Beijing as an example. ISPRS Ann. Photogramm. Remote Sens. Spatial Inf. Sci. 2017. Vol. IV-2/W2. P. 123-129. https://doi.org/10.5194/isprs-annals-IV-2-W2-123-2017

Hassani F. Documentation of cultural heritage; techniques, potentials, and constraints. Int. Arch. Photogramm. Remote Sens. Spatial Inf. Sci. 2015. Vol. XL-5/W7. P. 207-214. https://doi.org/10.5194/isprsarchives-XL-5-W7-207-2015

Hassani F., Rafiee M. An experience in cultural heritage documentation in Iran using a low-cost technique. Int. Arch. Photogramm. Remote Sens. Spatial Inf. Sci. 2013. Vol. XL5/W1. P. 313-318.

Kersten T., Lindstaedt M., Maziull L., Schreyer K., Tschirschwitz F., Holm K. 3D recording, modelling and visualisation of the fortification Kristiansten in Trondheim (Norway) by photogrammetric methods and terrestrial laser scanning in the framework of Erasmus programmes. Int. Arch. Photogramm. Remote Sens. Spatial Inf. Sci. 2015. Vol. XL5/W4. P. 255-262. https://doi.org/10.5194/isprsarchives-XL-5W4-255-2015

Kravchenko, I., Luhmann, T., and Shults, R. 2016, Concept and practice of teaching technical university students to modern technologies of 3D data acquisition and processing: A case study of close-range photogrammetry and terrestrial laser scanning, Int. Arch. Photogramm. Remote Sens. Spatial Inf. Sci., XLI-B6, 65-69, https://doi.org/10.5194/isprs-archivesXLI-B6-65-2016.

Levin, E., Vach, K., and Shults, R., 2017 Development of the new educational content "Small UAS in civil engineering 
application scenarios", ISPRS Ann. Photogramm. Remote Sens. Spatial Inf. Sci., IV-5/W1, 29-33, https://doi.org/10.5194/isprsannals-IV-5-W1-29-2017.

Logothetis S., Delinasiou A., Stylianidis E. Building information modelling for cultural heritage: A review. ISPRS Ann. Photogramm. Remote Sens. Spatial Inf. Sci. 2015. Vol. II5/W3. P. 177-183. https://doi.org/10.5194/isprsannals-II-5-W3$177-2015$

Luhmann T., Robson S., Kyle S., Boehm J. Close-range photogrammetry and 3D imaging. Berlin/Boston: Walter De Gruyter GmbH, 2014. 691 p.

Murtiyoso A., Koehl M., Grussenmeyer P., Freville T. Acquisition and processing protocols for UAV images: 3D modeling of historical buildings using photogrammetry. // ISPRS Ann. Photogramm. Remote Sens. Spatial Inf. Sci. 2017. Vol. IV-2/W2. P. 163-170. https://doi.org/10.5194/isprs-annalsIV-2-W2-163-2017

Patias P., Kaimaris D., Georgiadis Ch., Stamnas A., Antoniadis D., Papadimitrakis D. 3D mapping of cultural heritage: special problems and best practices in extreme case-studies. Int. Arch. Photogramm. Remote Sens. Spatial Inf. Sci. 2013. Vol. II-5/W1. P. 223-228. https://doi.org/10.5194/isprsannals-II-5-W1-2232013

Santise M., Thoeni K., Roncella R., Sloan S.W., Giacomini A. Preliminary tests of a new low-cost photogrammetric system. Int. Arch. Photogramm. Remote Sens. Spatial Inf. Sci. 2017. Vol. XLII-2/W8. P. 229-236. https://doi.org/10.5194/isprsarchives-XLII-2-W8-229-2017

Shults, R., 2017 New opportunities of low-cost photogrammetry for culture heritage preservation, Int. Arch. Photogramm. Remote Sens. Spatial Inf. Sci., XLII-5/W1, 481-486, https://doi.org/10.5194/isprs-archives-XLII-5-W1-481-2017.

Shults, R., Krelshtein, P., Kravchenko, I., Rogoza, O., Kyselov, O., 2017. Low-Cost Photogrammetry for Culture Heritage, 10th International Conference "Environmental Engineering", Lithuania. https://doi.org/10.3846/enviro.2017.237

Zacharek M., Delis P., Kedzierski M., Fryskowska A. Generating accurate 3D models of architectural heritage structures using low-cost camera and open source algorithms. Int. Arch. Photogramm. Remote Sens. Spatial Inf. Sci. 2017. Vol. XLII-5/W1. P. 99-104. https://doi.org/10.5194/isprsarchives-XLII-5-W1-99-2017 